\title{
B- and T-lymphocyte attenuator stimulation protects against atherosclerosis by regulating follicular B cells
}

\section{Hidde Douna $\mathbb{1}^{1}{ }^{1}$, Jacob Amersfoort $\mathbb{1}^{1}{ }^{1}$, Frank H. Schaftenaar ${ }^{1}$, Mara J. Kröner ${ }^{1}$, Máté G. Kiss" ${ }^{2}$, Bram Slütter', Marie A. C. Depuydt (1) ${ }^{1}$, Mireia N. A. Bernabé Kleijn', Anouk Wezel ${ }^{3}$, Harm J. Smeets ${ }^{3}$, Hideo Yagita ${ }^{4}$, Christoph J. Binder (1) ${ }^{2}$, I. Bot (1) ${ }^{1}$, Gijs H. M. van Puijvelde ${ }^{1}$, Johan Kuiper ${ }^{1}$, and Amanda C. Foks $\mathbb{1}^{1}{ }^{1} *$}

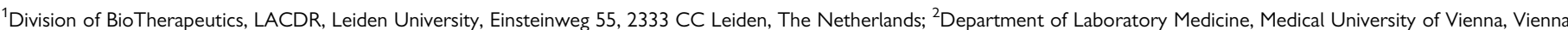
1090, Austria; ${ }^{3}$ Department of Surgery, HMC Westeinde, The Hague, The Netherlands; and ${ }^{4}$ Department of Immunology, Juntendo University School of Medicine, Tokyo 113-8421, Japan

Received 20 August 2018; revised 3 April 2019; editorial decision 9 May 2019; accepted 10 May 2019

Time for primary review: 16 days

Aims

The immune system is strongly involved in atherosclerosis and immune regulation generally leads to attenuated atherosclerosis. B- and T-lymphocyte attenuator (BTLA) is a novel co-receptor that negatively regulates the activation of $B$ and T cells; however, there have been no reports of BTLA and its function in atherosclerosis or cardiovascular disease (CVD). We aimed to assess the dominant BTLA expressing leucocyte in CVD patients and to investigate whether BTLA has a functional role in experimental atherosclerosis.

Methods

and results

We show that BTLA is primarily expressed on B cells in CVD patients and follicular B2 cells in low-density lipoprotein receptor-deficient $\left(L d l r^{-1}\right)$ mice. We treated $L d l r^{-1-}$ mice that were fed a western-type diet (WTD) with phosphate-buffered saline, an isotype antibody, or an agonistic BTLA antibody (3C10) for 6 weeks. We report here that the agonistic BTLA antibody significantly attenuated atherosclerosis. This was associated with a strong reduction in follicular B2 cells, while regulatory B and T cells were increased. The BTLA antibody showed similar immunomodulating effects in a progression study in which $L d l r^{-1}$ mice were fed a WTD for 10 weeks before receiving antibody treatment. Most importantly, BTLA stimulation enhanced collagen content, a feature of stable lesions, in pre-existing lesions.

Conclusion Stimulation of the BTLA pathway in $\mathrm{Ldlr}^{-1-}$ mice reduces initial lesion development and increases collagen content of established lesions, presumably by shifting the balance between atherogenic follicular $B$ cells and atheroprotective $\mathrm{B}$ cells and directing $\mathrm{CD}^{+} \mathrm{T}$ cells towards regulatory $\mathrm{T}$ cells. We provide the first evidence that $\mathrm{BTLA}$ is a very promising target for the treatment of atherosclerosis.

Keywords Arteriosclerosis • Immune system • B-lymphocyte • Co-receptor • BTLA

\section{Introduction}

Inflammation is a key process in the development of atherosclerosis. ${ }^{1}$ Components of both the innate and adaptive immune system contribute significantly to the pathology of atherosclerosis. The connection be- tween these two arms of the immune system is provided by professional antigen presenting cells (APCs). Dendritic cells and macrophages are well-known APCs, but nowadays the role of B cells as potent APCs is also increasingly recognized. Next to processing and presenting antigens 
to lymphocytes, these cells provide additional stimuli in the form of coreceptors. In fact, the activation of $T$ cells and $B$ cells is tightly controlled by these immune checkpoint proteins. ${ }^{2}$ APCs have a wide-ranging variety of both stimulatory and inhibitory immune checkpoint proteins. In general, stimulatory co-receptors are found to be atherogenic, while inhibitory proteins attenuate atherosclerosis. ${ }^{2}$

B- and T-lymphocyte attenuator (BTLA, also known as CD272) is a relatively recently described co-inhibitory receptor belonging to the immunoglobulin superfamily. It was originally identified in search for a $T$ helper type 1 (Th1) marker ${ }^{3}$ and it has been demonstrated that BTLA interacts with herpesvirus entry mediator (HVEM). ${ }^{4} \mathrm{HVEM}$ is part of the tumour necrosis factor receptor superfamily and the BTLA-HVEM interaction is an unique example of cross-talk between the immune checkpoint proteins of both superfamilies. Ligation of HVEM to BTLA generates an inhibitory signal, which is supported by the fact that BTLA-deficient $T$ and $B$ cells are hyperresponsive. ${ }^{3,5,6}$ In addition, BTLA-deficient mice show a marked phenotype of auto-immunity with increased levels of auto-antibodies, spontaneous development of autoimmune-like hepatitis, ${ }^{7}$ and increased susceptibility towards experimental autoimmune encephalomyelitis. ${ }^{3}$ In humans, BTLA seems to function similarly since BTLA cross-linking on human $T$ cells leads to suppressed proliferation and cytokine production. ${ }^{8}$ Moreover, in patients with rheumatoid arthritis ${ }^{9}$ and type 1 diabetes ${ }^{10}$ functional polymorphisms or altered expression levels of BTLA have been found.

Hence, since its discovery as an inhibitory co-receptor, BTLA has attracted a lot of attention as a potential target for immunotherapy. While in oncology novel ways to block BTLA are explored, ${ }^{11}$ it has been shown that in autoimmune or inflammatory disorders stimulation of BTLA is a more promising option. For instance, agonistic antibodies for BTLA have been used in experimental models of Behcet's disease, ${ }^{12}$ cerebral malaria, ${ }^{13}$ graft-versus-host disease, ${ }^{14}$ and cardiac allograft rejection. ${ }^{15}$ These data clearly indicate that the BTLA pathway is a potent option for the treatment of autoimmune disorders. Up to date, there have been no reports of BTLA and if it is involved in atherosclerosis or CVD.

In this study, we therefore aimed to characterize BTLA-expressing leucocytes in CVD patients and to investigate whether BTLA has a functional role in atherosclerosis by using a non-depleting agonistic BTLA antibody.

\section{Methods}

\subsection{Human samples}

Eleven anonymous atherosclerotic plaques and blood samples were collected post-operatively from carotid or femoral endarterectomy surgeries performed in 2017 and 2018 at the Haaglanden Medical Center (HMC), Westeinde, The Hague, The Netherlands. The collection of samples was performed conform the declaration of Helsinki regarding ethical principles for medical research involving human subjects (METC registration number 17-046). All atherosclerotic samples were processed to single-cell suspensions as described previously. ${ }^{16}$ In short, cell suspensions from human atherosclerotic plaques were obtained upon digestion with collagenase IV (Gibco) and DNase (Sigma) for $30 \mathrm{~min}$ at $37^{\circ} \mathrm{C}$ prior to single-cell separation through a $70 \mu \mathrm{m}$ cell strainer. Red blood cells in blood samples were lysed using ACK lysis buffer. All human white blood cell populations were characterized by flow cytometry based on the expression of the pan-leucocyte marker CD45. Gating strategies are shown where appropriate.

\subsection{Animals}

Female low-density lipoprotein receptor-deficient mice $\left(L d r^{-1-}\right)$ were bred in house and kept under standard laboratory conditions. Mice were fed a western-type diet (WTD) containing $0.25 \%$ cholesterol and 15\% cocoa butter (Special Diet Services, Witham, Essex, UK). Diet and water were provided ad libitum. All injections were administered i.p. in a total volume of $100 \mu \mathrm{L}$. During the experiments, mice were weighed, and blood samples were obtained by tail vein bleeding. At the end of experiments, mice were anaesthetized by a subcutaneous injection of a cocktail containing ketamine $(40 \mathrm{mg} / \mathrm{mL})$, atropine $(50 \mu \mathrm{g} / \mathrm{mL})$, and sedazine $(6.25 \mathrm{mg} / \mathrm{mL})$. Mice were bled by femoral artery transection followed by perfusion with phosphate-buffered saline (PBS) through the left cardiac ventricle. All animal work was approved by the Leiden University Animal Ethics Committee and the animal experiments were performed conform the guidelines from Directive 2010/63/EU of the European Parliament on the protection of animals used for scientific purposes.

\subsection{In vivo experiments}

Two separate diet-induced atherosclerosis experiments were performed in this study; an atherosclerosis initiation and an atherosclerosis progression experiment. For the initiation experiment, female $\mathrm{Ldll}^{-/-}$ mice ( $n=11-12$ /group) were fed a WTD for 6 weeks, while either receiving an i.p. injection of PBS, an appropriate Armenian hamster isotype antibody (Innovative Research, Novi, Ml; $100 \mu \mathrm{g} /$ injection), or a nondepleting agonistic BTLA antibody ${ }^{15}$ (3C10; $100 \mu$ g/injection) twice a week. For the progression experiment, female $L d l^{-/-}$mice $(n=11-12 /$ group) were first fed a WTD for 10 weeks before initiating the same treatment with an isotype antibody or an agonistic BTLA antibody for 6 weeks. At the start of the treatment, one group of mice was sacrificed as a baseline group. A third in vivo experiment was performed to investigate the direct effect of BTLA blockade on T cells. Female $L d r^{-1-}$ mice ( $n=5-6 /$ group) were fed a WTD for 2 weeks while, similarly as described above, receiving i.p. injections of either PBS, isotype control, BTLA, or receiving once a week anti-CD20 (Genentech, clone 5D2; $250 \mu \mathrm{g} /$ injection) to deplete $\mathrm{B}$ cells, or a combination of BTLA and antiCD20.

\subsection{Flow cytometry}

For flow cytometry analysis, Fc receptors of single-cell suspensions of the mediastinal lymph node, spleen, blood, or peritoneum were blocked with an unconjugated antibody against CD16/CD32. Samples were then stained with a fixable viability marker (ThermoScientific) to select live cells and anti-mouse fluorochrome-conjugated antibodies (see Supplementary material online, Table SI).

For the analysis of IL-10+ $\mathrm{B}$ cells, single-cell suspensions were stimulated for $5 \mathrm{~h}$ with LPS $(50 \mu \mathrm{g} / \mathrm{mL})$, PMA $(50 \mathrm{ng} / \mathrm{mL})$, ionomycin $(500 \mathrm{ng} /$ $\mathrm{mL})$, and monensin $(2 \mu \mathrm{M})$. FACS analysis was performed on a FACSCanto II (Becton Dickinson) or a Cytoflex S (Beckman Coulter) and the acquired data were analysed using Flowjo software. Gates were set according to unstimulated controls (only treated with monensin) or to isotype and fluorescence minus one controls.

\subsection{Serum measurements}

After euthanasia, orbital blood was collected in EDTA-coated tubes. Whole blood cell counts were analysed using the XT-2000iV haematology analyser (Sysmex Europe GMBH, Norderstedt, Germany). Serum was acquired by centrifugation and stored at $-20^{\circ} \mathrm{C}$ until further use. The total cholesterol levels in serum were determined using enzymatic 
colorimetric procedures (Roche/Hitachi, Mannheim, Germany). Precipath (Roche/Hitachi) was used as an internal standard. Total serum titers of $\lg M$, $\lg G 1$, $\lg$ G2c, and antigen-specific antibodies were quantified by ELISA as previously described. ${ }^{17}$

\subsection{B-cell culture}

$\mathrm{B}$ cells were isolated from female $\mathrm{Ldl} r^{-/-}$mice using $\mathrm{CD} 19^{+}$microbeads (Miltenyi Biotec) and cultured in complete RPMI medium in the presence of different concentrations of the agonistic BTLA antibody or recombinant murine HVEM Fc (R\&D systems). After $24 \mathrm{~h}$, cells were harvested and either stained using an Annexin- $V$ Apoptosis detection kit (ThermoFisher) or used for routine flow cytometry.

$B$ cells were also isolated from mice treated with PBS or the BTLA agonistic antibody for 2 weeks. Isolated B cells were co-cultured with isolated $\mathrm{CD}^{+}{ }^{+} \mathrm{T}$ cells from OT-II mice in the presence of OVA323 peptide $(1 \mu \mathrm{g} / \mathrm{mL})$. After $72 \mathrm{~h}$, cells were harvested and analysed with flow cytometry.

\subsection{Histology}

To determine plaque size, cryosections $(10 \mu \mathrm{m})$ of the aortic root were stained with Oil-Red-O and haematoxylin (Sigma-Aldrich). Sections with the largest lesion plus four flanking sections were analysed for lesion size and two flanking sections for lesion composition. Collagen content in the lesion was assessed with a Masson's trichrome staining according to the manufacturers protocol (Sigma-Aldrich). Corresponding sections on separate slides were also stained for monocyte/macrophage with a MOMA-2 antibody (1:1000, AbD Serotec) followed by a goat anti-rat lgG-alkaline phosphatase antibody (1:100, Sigma-Aldrich). Colour development was achieved using nitro blue tetrazolium and 5-bromo-4chloro-3-indolyl phosphate as enzyme substrates. The relative amount of collagen and percentage of macrophages in the lesions is expressed as the ratio between the collagen- or MOMA-2-positive and the total lesion surface area. Smooth muscle cells were stained with an $\alpha$-smooth muscle cell-actin ( $\alpha$ SMA) antibody (clone 1A4, Sigma-Aldrich) and SMC positive areas were related to the total intima surface area. The necrotic core was defined as the a-cellular, debris-rich plaque area as percentage of total plaque area. CD4 ${ }^{+}$T cell (RM4-5, 1:90, ThermoFisher) and B cell (RA3-6B2, 1:100, BD Biosciences) analysis in the lesion was assessed using a rat monoclonal antibody and a secondary rabbit anti-rat antibody (BA-4001, Vector). Followed by the Vectastain ABC kit (PK-4000, Vector) and colour was developed using the ImmPact Novared kit (Vector). Sections where no primary antibody was used and were taken as negative controls. All slides were analysed with a Leica DM-RE microscope and LeicaQwin software (Leica Imaging Systems).

For fluorescent histology, cryosections $(10 \mu \mathrm{m})$ of the spleen were stained with anti-mouse antibodies against CD3 (SP7) and B220 (RA36B2). Subsequently, sections were stained with secondary goat-anti rabbit and goat-anti rat antibodies conjugated to Alexa fluor 647 and Alexa fluor 488 (Abcam). Nuclei were visualized using the Fluoroshield mounting medium containing DAPI. Sections were captured using a Nikon TiE 2000 confocal microscope with a 20x plan apochromat objective and analysed with Nis Elements version 4.3.

\subsection{Statistics}

All data are expressed as mean \pm SEM. Data were tested for significance using a Student's $t$-test for two normally distributed groups. Data from three groups or more were analysed by an ordinary one-way ANOVA test followed by a Holm-Sidak post hoc test. Data from experiments with two or more variables were analysed by a two-way ANOVA test followed by a Sidak post hoc test. $P$-values of $<0.05$ were considered significant. All statistical analysis was performed using GraphPad Prism 7.0.

\section{Results}

\subsection{B cells from cardiovascular disease patients display strong BTLA expression}

Currently, there is no data available regarding BTLA in patients with cardiovascular disease (CVD). Hence, we obtained blood and lesions from patients that underwent an endarterectomy to assess the expression of BTLA on leucocytes. We found that almost $90 \%$ of the circulating $\mathrm{CD} 19^{+} \mathrm{CD} 20^{+} \mathrm{B}$ cells expressed high levels of BTLA, while $\mathrm{CD}^{+} \mathrm{T}$ cells $(8.5 \%)$ and monocytes (5.2\%) showed a much more moderate expression and granulocytes expressed only minimal levels of BTLA (Supplementary material online, Figure SI, Figure $1 A$ and $B$ ). Within the lesion, the greater majority of leucocytes, including $B$ cells, do not express BTLA. This is partly caused by a difference in B-cell subsets that reside in the lesion compared with blood (Figure 1B). The circulating B-cell population is mostly composed of naive $B$ cells that express the highest levels of BTLA, whereas in the lesion we mainly found effector B-cell subtypes that have lower BTLA expression. This data suggests that BTLA is most abundantly expressed on circulating $B$ cells in patients with CVD, while this expression seems to be lost on B cells that are present in the lesion.

\subsection{BTLA is predominantly expressed by follicular B2 cells in $\mathrm{Ldll}^{-1-}$ mice}

Given the high expression of BTLA on peripheral B cells from CVD patients and its inhibitory role, we wanted to further explore the potential of BTLA as a therapeutic target to treat atherosclerosis. First, we characterized the expression profile of BTLA on immune cells using spleens from low-density lipoprotein receptor-deficient $\left(L d r^{-1-}\right)$ mice. Similar to human leucocytes, we found that BTLA was predominantly expressed on $\mathrm{B}$ cells, with relatively low expression on $\mathrm{CD}^{+}{ }^{+} \mathrm{T}$ cells, $\mathrm{CD}^{+} \mathrm{T}$ cells, and innate immune cells (Figure $2 \mathrm{~A}$ and Supplementary material online, Figure SIIA). Moreover, we did not find any differences in BTLA expression between $\mathrm{CD}^{+}{ }^{+} \mathrm{T}$ helper cell subsets in contrast to previous work $^{3}$ (Supplementary material online, Figure SIIB). Interestingly, we again discovered a significant difference in BTLA expression between B-cell subsets, with conventional follicular B2 cells being the most dominant BTLA-expressing leucocyte (Figure 2B).

\subsection{BTLA activation reduces initial atherosclerosis}

The role of $\mathrm{B}$ cells in atherosclerosis has been quite controversial and seems to be highly dependent on the B-cell subset. ${ }^{18}$ Previously, it has been reported that follicular B-cells aggravate atherosclerosis. ${ }^{19-21}$ Since BTLA was most abundantly expressed on follicular B cells, we hypothesized that an agonistic BTLA antibody could inhibit follicular B cells in $\mathrm{Ldll}^{-/-}$mice, leading to attenuated atherosclerosis. We therefore treated female $L d l r^{-1}$ mice twice a week with either PBS, an isotype control antibody, or an agonistic BTLA antibody (3C10) for 6 weeks while being fed a WTD (Figure 2C). The 3C10 antibody has previously been described as a non-depleting agonistic BTLA antibody. ${ }^{15}$ Treatment with the BTLA antibody did not affect body weight or total serum cholesterol levels (Figure 2D and E). Stimulation/agonism of BTLA resulted in a significant $43 \%$ reduction in lesion size in the aortic root compared with PBS- 
A

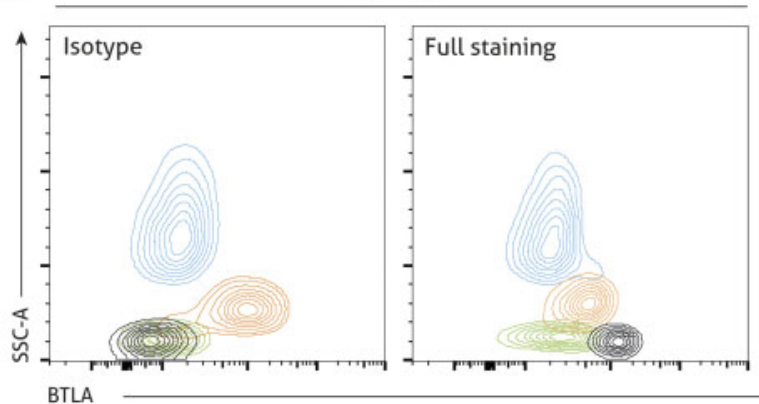

Lesion

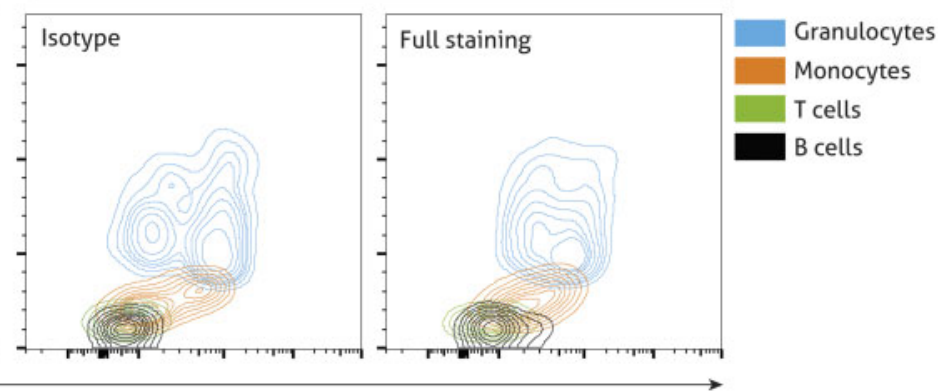

BTLA expression of $B$ cell subsets

B BTLA expression

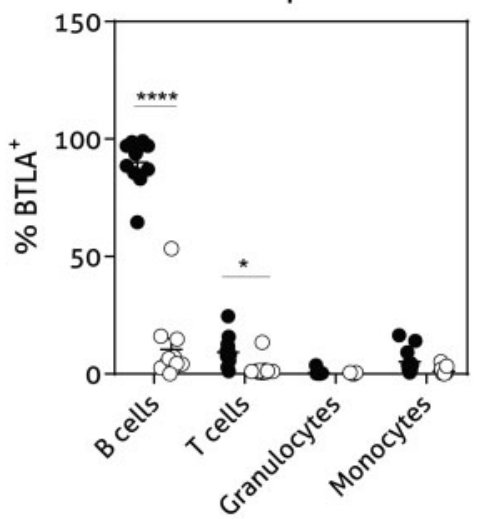

B cell subsets

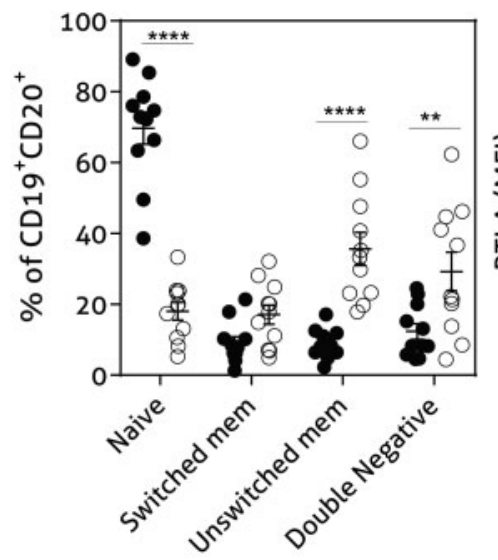

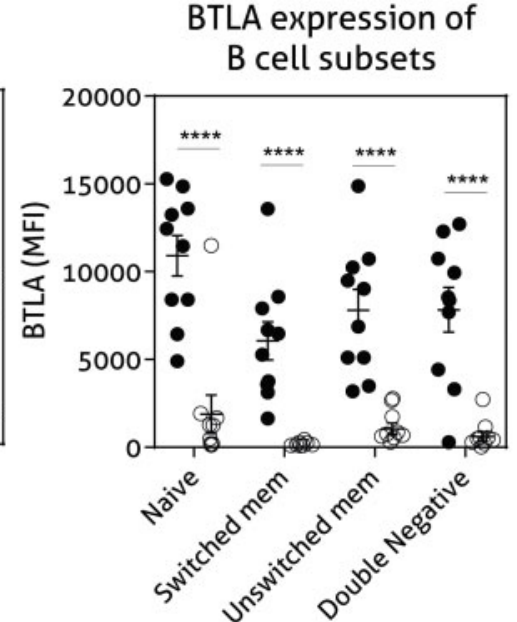

- Blood

- Lesion

Figure I B cells from CVD patients display strong BTLA expression. Flow cytometry was applied on blood and lesions from CVD patients to identify BTLA expression on major leucocyte populations. (A) A flowcharts of BTLA expression by major leucocyte populations. (B) Quantification of BTLA expression by leucocyte populations and B-cell subsets. A two-way ANOVA followed by a Sidak post hoc test was performed. Data are shown as mean \pm SEM, $n=$ $11(* P<0.05, * * P<0.01, * * * * P<0.0001 \mathrm{vs}$. isotype).

treated mice and a significant $37 \%$ reduction compared with isotypetreated mice (Figure 2F). Correspondingly, we found that lesions from mice treated with the BTLA antibody predominantly consisted of macrophages and relatively low amounts of collagen (Supplementary material online, Figure SIII), illustrating an early lesion phenotype. In contrast, lesions from mice treated with PBS or the isotype control, showed a more advanced phenotype with relatively more collagen and less macrophage content (Supplementary material online, Figure SIII).

\subsection{Activation of BTLA leads to strong follicular B2 cell reduction}

To assess whether the reduced atherosclerosis could be attributed to altered immune functions, we analysed circulating leucocytes. We found a major reduction in total white blood cells in mice treated with the BTLA antibody compared with PBS- or isotype-treated mice (Supplementary material online, Figure SIV). This was primarily due to a major decrease in lymphocytes and a smaller decrease in monocytes. Since monocytes and macrophages contribute significantly to initial lesion formation, we measured monocytes and monocyte subsets with flow cytometry but we could not identify a difference between BTLA-treated mice and PBS- or isotype-treated mice (Supplementary material online, Figure SV). The strong lymphocyte reduction was primarily due to a sharp decrease in B cells in the blood and a similar effect was found in the spleen, lymph node, and peritoneum (Figure 3A, Supplementary material online, Figure SVIA). Moreover, analysis of the B cell lineages showed that BTLA agonism particularly led to a reduction in $\mathrm{B} 2$ cells and a relative increase in the percentage of B1 cells (Figure 3B, Supplementary material online, Figure SVIB). More specifically, we found that the percentage of follicular B2 cells decreased, while marginal zone $B$ cells increased in mice treated with the BTLA antibody compared with mice treated with PBS or isotype control (Figure 3C, Supplementary material online, Figure SVIC). In line with these findings, fluorescent immunohistology on spleen cryosections revealed that BTLA stimulation led to a decrease of $B$ cells immediately surrounding the $T$ cell areas, which corresponds to a reduction in follicular B cells (Figure 3D).

Mechanistically, we show that BTLA agonism, similarly as BTLAHVEM signalling, increased apoptosis and reduced activation in follicular B cells (Supplementary material online, Figure SVII). Since follicular B cells are often involved in the humoral immunity, we next determined whether BTLA treatment reduced atherosclerosis by altering antibody responses. However, we did not find relevant differences in either total or malondialdehyde-LDL and oxidized-LDL-specific serum titer levels that could explain the ameliorated atherosclerosis (Supplementary material online, Figure SVIII). 
A

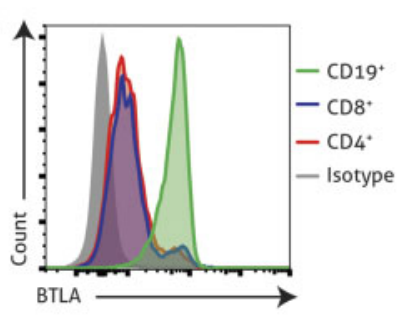

C

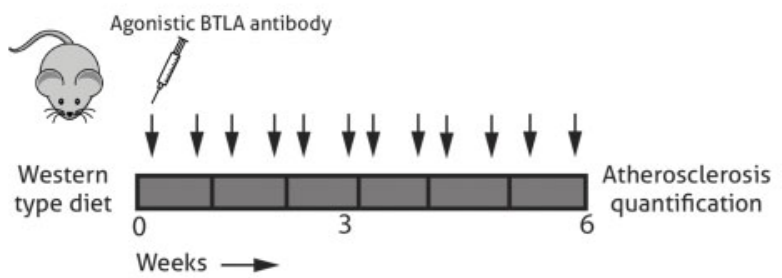

$\mathbf{F}$

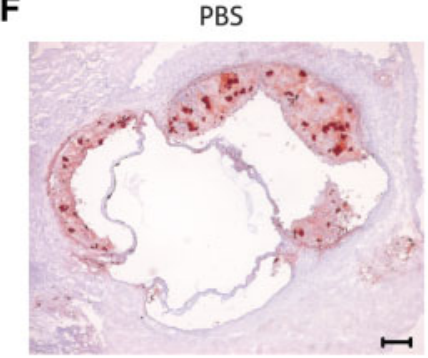

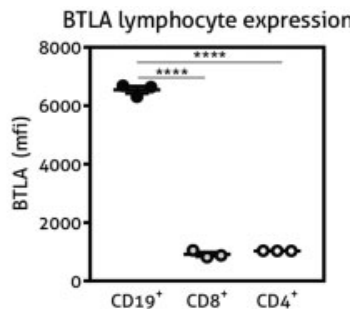

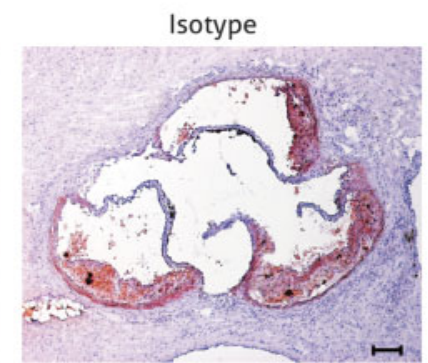

B
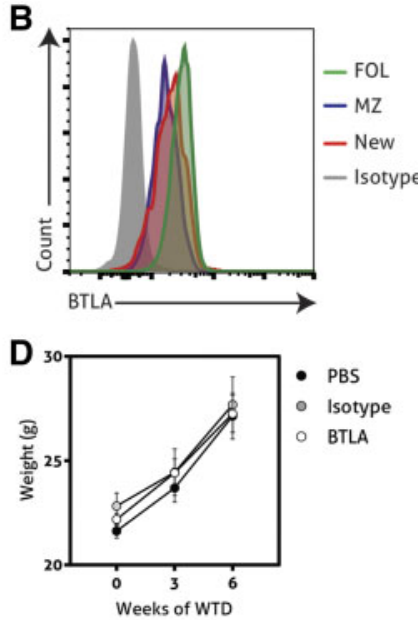

BTLA

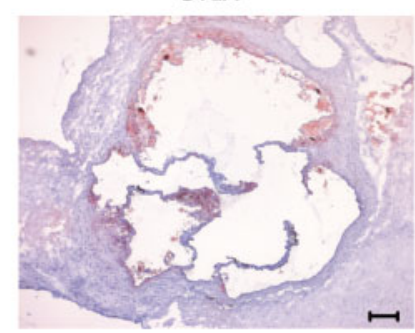

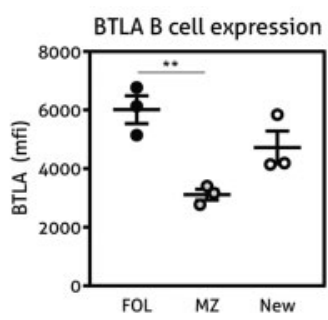

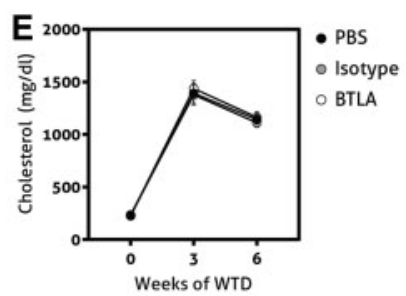

Lesion size

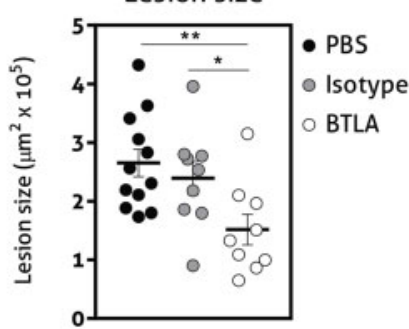

Figure 2 Activation of BTLA reduces initial atherosclerosis. (A) Flow overlays and quantification of BTLA expression in leucocyte populations and (B) spe-

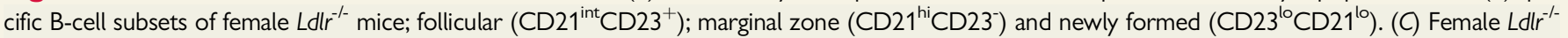
mice were treated twice a week intraperitoneally with PBS, an isotype antibody, or an agonistic BTLA antibody for 6 weeks, while being fed a western-type diet. (D) Mice were weighed and $(E)$ serum cholesterol levels were determined. $(F)$ Oil-Red-O and haematoxylin staining in aortic root sections and lesion size quantification. Scale bars are $100 \mu \mathrm{m}$. An ordinary one-way ANOVA test followed by a Holm-Sidak post hoc test was performed. Data are shown as mean \pm SEM, $n=3(A / B)$ and $n=9 / 12(C-F)(* P<0.05, * * P<0.01$, ****P<0.0001).

\subsection{Activation of BTLA leads to increased regulatory $B$ cells}

Besides the conventional B1 and B2 cells, we nowadays know that there are many novel $B$-cell subsets that can regulate the immune response. ${ }^{18}$ Although most of these regulatory B cells (Bregs) ultimately act via interleukin-10 (IL-10), they can be identified by different extracellular markers, ${ }^{22}$ such as CD1 $\mathrm{d}^{\text {hi }} \mathrm{CD} 5^{+}$expression, ${ }^{23}$ and T-cell immunoglobulin and mucin domain 1 (TIM-1). ${ }^{24}$ We found that BTLA was expressed on all of these Breg subsets (Supplementary material online, Figure SIIC). Accordingly, $\mathrm{Ldlr}^{-/-}$mice treated with agonistic BTLA showed a very strong increase in B10 cells and $\mathrm{TIM}-1^{+}$B cells in the spleen, lymph nodes, and blood when compared with treatment with PBS or isotype control (Figure $4 A$ and $B$ ). In addition, we measured the direct secretion of IL- 10 by $B$ cells and found that BTLA stimulation significantly increased the percentage of B cells that secreted IL-10 compared with the PBS or isotype control groups (Figure 4C).

\subsection{Activation of BTLA leads to a protective T-cell response}

Treatment with the BTLA antibody resulted in a B cell pool that is highly enriched in marginal zone $B$ cells and Breg cells, which can both inhibit the $\mathrm{CD}^{+}{ }^{+}$-cell response. ${ }^{22,25}$ Hence, we assessed the number of lesional $\mathrm{CD} 4^{+} \mathrm{T}$ cells and found a marked reduction in infiltrating $\mathrm{CD} 4^{+}$
T cells in BTLA-treated mice compared with PBS- or isotype-treated mice (Figure $5 A$ ). Corroborating with earlier data, ${ }^{21}$ we did not find any relevant numbers of $\mathrm{B}$ cells in the lesion at this stage (Supplementary material online, Figure SIX). We thus reasoned that the $\mathrm{CD}^{+}{ }^{+} \mathrm{T}$-cell regulation had taken place peripherally as shown in earlier reports. ${ }^{21}$ Although we did not find a difference in total splenic $\mathrm{CD} 4^{+} \mathrm{T}$ cells, we found that BTLA-treated mice contained more effector and less naïve $T$ cells than PBS- or isotype-treated mice (Figure 5B). More specifically, we observed an increase in regulatory (Treg) and Th17 cells in BTLA-treated mice, while no effects were found for Th1 or Th2 cells (Figure 5C). It is widely recognized that Tregs are atheroprotective ${ }^{26}$ and Th17 cells have also been shown to protect against atherosclerosis in a setting with reduced B cells. ${ }^{21}$ This indicates that treatment with the BTLA antibody polarized the $\mathrm{CD}^{+}{ }^{+} \mathrm{T}$-cell response in vivo towards a more atheroprotective response. The reduced activation of $\mathrm{CD}^{+} \mathrm{T}$ cells in BTLA-treated mice was not dependent on changes in DCs, as we did not find differences in total DCs or regulatory DCs (DEC- $205^{+} \mathrm{CD} 8^{+}$) between PBS-, isotype-, or BTLA-treated mice (Supplementary material online, Figure $S X$ ). To test if the altered $C D 4^{+} T$-cell response after BTLA treatment was a direct effect of a different $B$ cell pool, we cultured OT-II CD4 ${ }^{+}$T cells with $B$ cells from mice treated with PBS or the BTLA antibody. We found that after $72 \mathrm{~h}$ of stimulation with OVA323 peptide, OT-II CD4 ${ }^{+}$ T-cells cultured in the presence of BTLA-treated B cells, showed a 

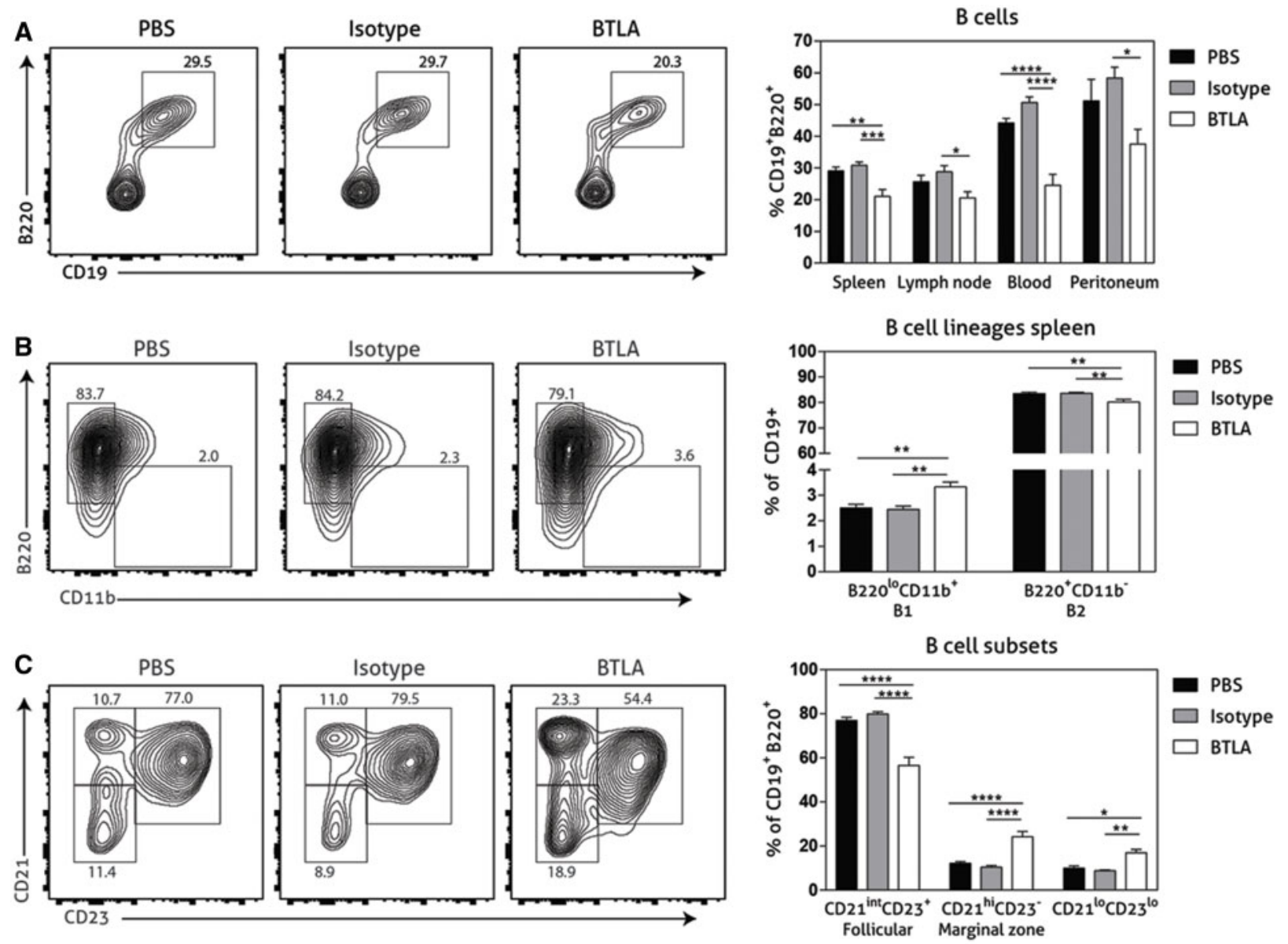

D

PBS

Isotype

\section{BTLA}
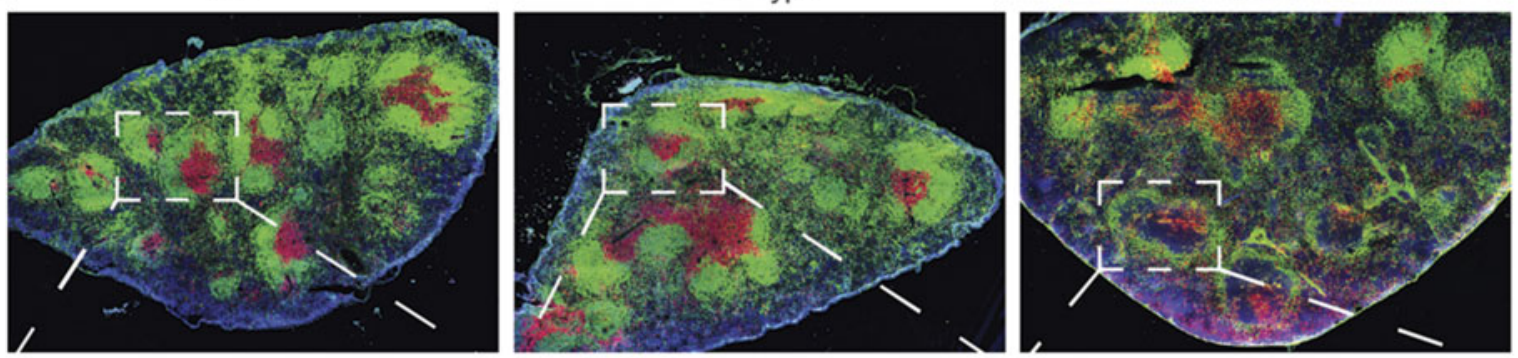

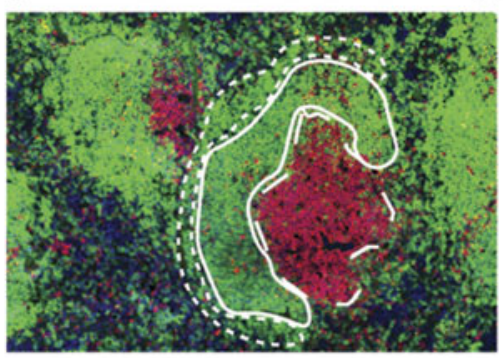

CD3 B220 DAPI

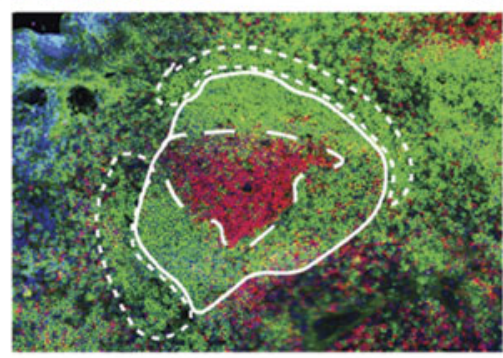

- T cell area

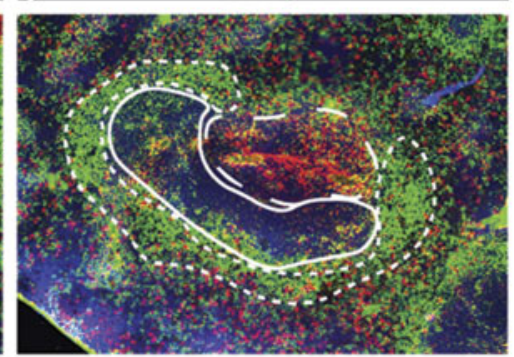

Follicles

Figure 3 Activation of BTLA leads to strong follicular B2 cell reduction. Female $L d l r^{-/}$mice were treated twice a week with PBS, an isotype antibody, or an agonistic BTLA antibody and fed a WTD for 6 weeks. (A) A flowcharts of splenocytes and quantifications of $B$ cells $\left(C D 19^{+} B 220^{+}\right)$in different organs. (B) A flowcharts of splenocytes and quantification of B1 cells $\left(C D 19^{+} \mathrm{CD} 11 \mathrm{~b}^{+} \mathrm{B} 220^{\circ}\right)$ and B2 cells $\left(\mathrm{CD} 19^{+} \mathrm{CD} 11 \mathrm{~b}^{-} \mathrm{B} 220^{+}\right)$in the spleen. $(C) \mathrm{A}$ flowcharts of splenocytes and quantification of follicular $\left(\mathrm{CD} 21^{\text {int }} \mathrm{CD} 23^{+}\right)$, marginal zone $\left(\mathrm{CD} 21^{\mathrm{hi}} \mathrm{CD} 23^{-}\right)$, and newly formed $\left(\mathrm{CD} 23^{\mathrm{lo}} \mathrm{CD} 21^{\circ}\right) \mathrm{B}$ cells in the spleen. $(\mathrm{D})$ Representative images of spleen sections stained for CD3 (red), B220 (green), and DAPI (blue). Regions of interest are visualized as depicted at higher magnifications. Scale bars are $100 \mu \mathrm{m}$ and $500 \mu \mathrm{m}$. An ordinary one-way ANOVA test followed by a Holm-Sidak post hoc test was performed. Data are shown as mean \pm SEM, $n=11-12(* P<0.05$, *** $P<0.01$, *** $P<0.001$, ***** $<0.0001)$. 
A

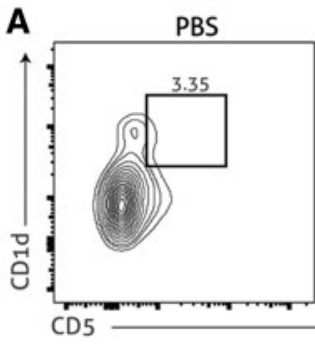

B

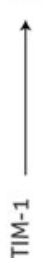

$\uparrow$

PBS

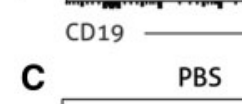

$\uparrow$

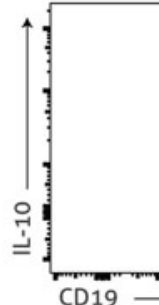

Isotype

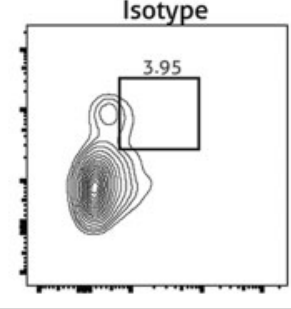

Isotype

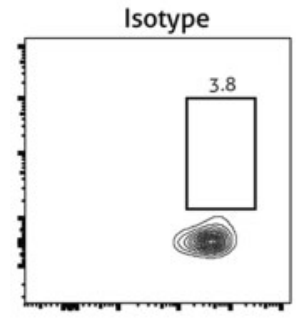

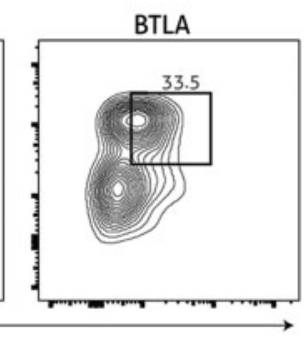
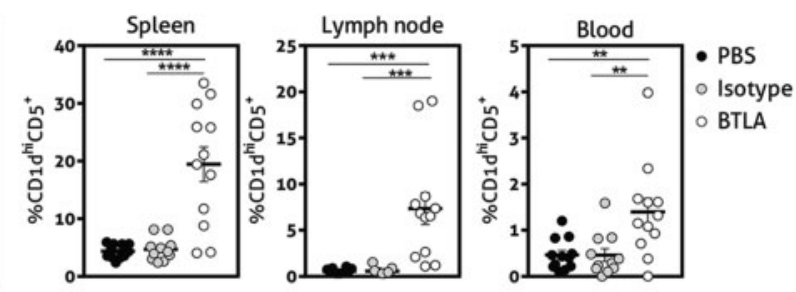

BTLA
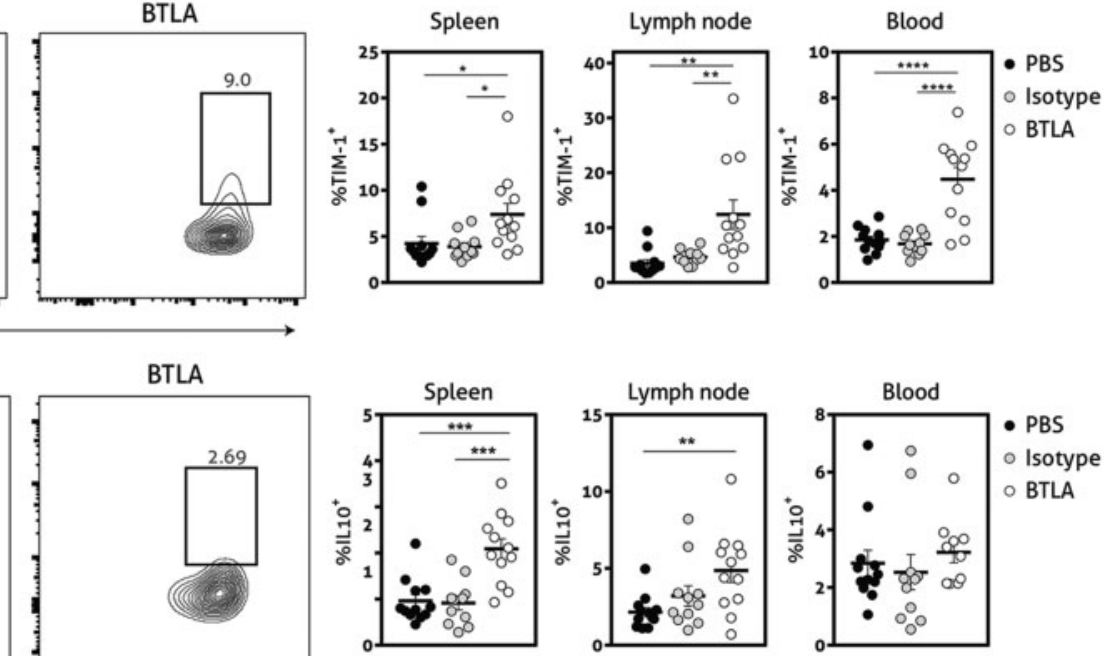

Figure 4 Activation of BTLA leads to increased regulatory B cells. Female Ldr ${ }^{-1-}$ mice were treated twice a week with PBS, an isotype antibody, or an agonistic BTLA antibody and fed a WTD for 6 weeks. A flowcharts for splenocytes and quantifications of regulatory B cells are shown for (A) B10 cells $\left(\mathrm{CD} 19^{+} \mathrm{CD} 1 \mathrm{~d}^{\text {hi }} \mathrm{CD} 5^{+}\right),(B) \mathrm{TIM}-1^{+} \mathrm{B}$ cells $\left(\mathrm{CD} 19^{+} \mathrm{TIM}-1^{+}\right)$, and $(C) \mathrm{LL}-10$ secreting $B$ cells $\left(\mathrm{CD} 19^{+} \mathrm{IL}-10^{+}\right)$. An ordinary one-way ANOVA test followed by a Holm-Sidak post hoc test was performed. Data are shown as mean \pm SEM, $n=11-12(* P<0.05, * * P<0.01, * * * P<0.001, * * * * P<0.0001)$.

marked increase in Tregs (Figure 5D). Moreover, CD4 ${ }^{+} \mathrm{T}$ cells from cocultures with BTLA-treated B cells showed a significant decrease in TNF $\alpha$ secretion, while IL-5 secretion was increased compared with $T$ cells from co-cultures with PBS-treated B cells (Figure 5E). Finally, we show that the anti-inflammatory T-cell response seen with BTLA agonism was not exclusively caused by changes seen in B cells, as BTLA treatment in B cell depleted mice also inhibits TNF $\alpha$ secretion by $\mathrm{CD}^{+} \mathrm{T}$ cells (Supplementary material online, Figure SXI).

Taken together, these data strongly indicate that the BTLA antibody reduced the peripheral activation of $\mathrm{CD} 4^{+} \mathrm{T}$ cells, both indirectly by altering the APC function of $B$ cells and by directly polarizing $C D 4^{+} \mathrm{T}$ cells, resulting in reduced lesional CD4 ${ }^{+} \mathrm{T}$ cells.

\subsection{Activation of BTLA enhances collagen content in established lesions}

Since most CVD patients that require medication already have wellestablished atherosclerosis, we also investigated the effects of the BTLA antibody on pre-existing lesions. Therefore, we fed $L d l r^{--}$mice a WTD for 10 weeks, after which we started the agonistic BTLA or isotype treatment for 6 weeks (Figure 6A). In line with our initial atherosclerosis study, we found a highly significant reduction in total $B$ cells in all relevant organs (Figure 6B) caused by a strong decrease in follicular B cells (Figure 6C). In contrast, IL-10 $\mathrm{B}$ cells (Figure 6D) and Tregs were increased
(Supplementary material online, Figure SXII). Although we did not find differences in lesion size between isotype- or BTLA-treated mice (Figure $6 E)$, we did observe that lesions of mice treated with the BTLA antibody contained significantly more collagen than lesions of mice treated with the isotype control (Figure 6F). Furthermore, lesional macrophages, smooth muscle cell content, and necrotic core area was determined (Supplementary material online, Figure SXIII).

\section{Discussion}

The discovery of immune checkpoint proteins has been a tremendous support in finding targets for immunomodulatory drugs. ${ }^{2}$ For many of these co-receptors, therapeutic antibodies or small molecules are now being tested in experimental animal models or in clinical trials. For the treatment of atherosclerosis and CVD, we still lack potent agents that target pathways other than cholesterol metabolism. There is an urgent need for such treatments, since the residual risk of CVD is still considerable even after effective cholesterol management. ${ }^{27}$ Moreover, the recent CANTOS trial demonstrated that anti-inflammatory therapy can significantly reduce the risk of cardiovascular events. ${ }^{28}$ In this study, we provide the first evidence that one of the newest additions to the coreceptor family, BTLA, is a very promising target for the treatment of atherosclerosis. 
A

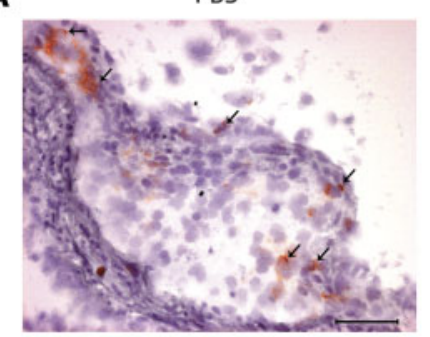

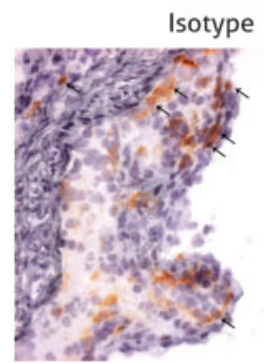

Isotype

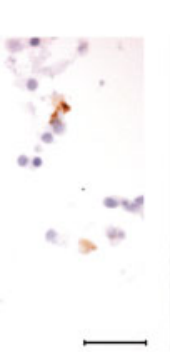

Isotype

B
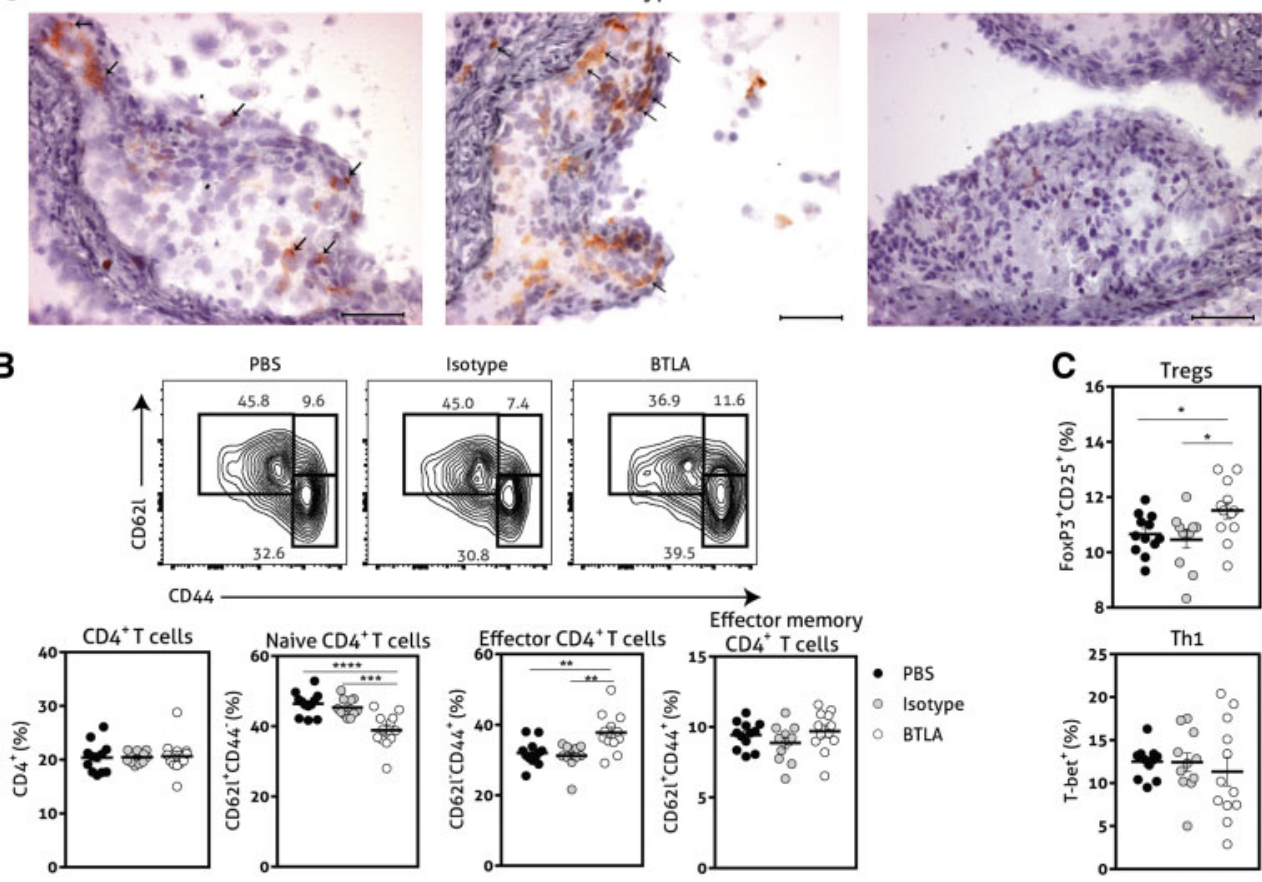

\section{$\mathrm{CD} 4{ }^{+} \mathrm{T}$ cells in the lesion}
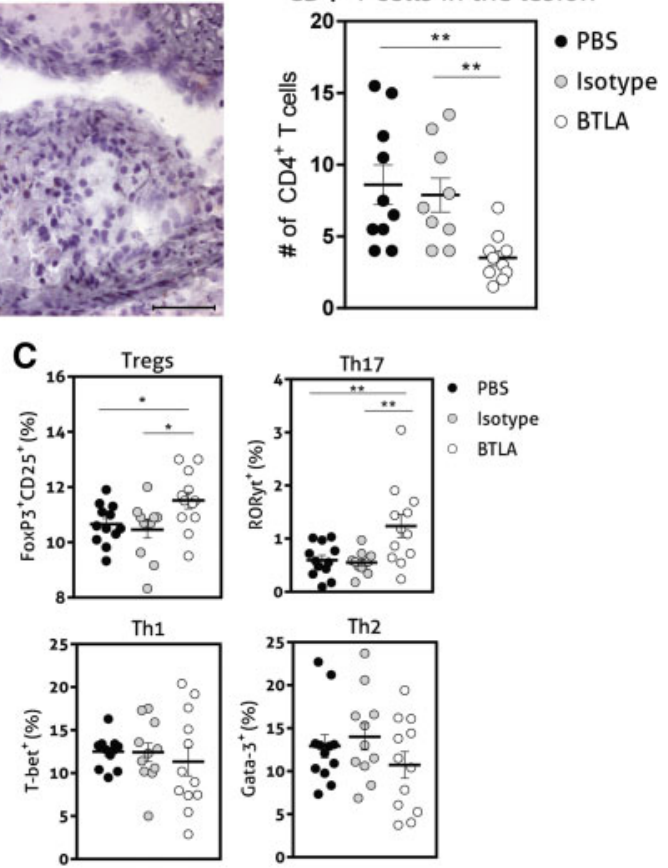

D

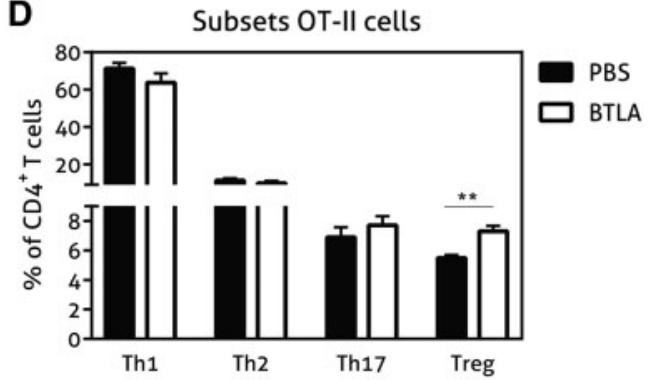

E

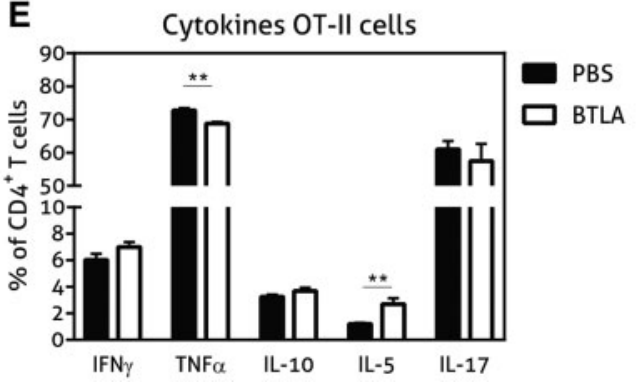

Figure 5 Activation of BTLA leads to decreased T-cell infiltration and activation. Female Ldlr $^{-/}$mice were treated twice a week intraperitoneally with PBS, an isotype antibody, or an agonistic BTLA antibody for 6 weeks while being fed a western-type diet. (A) Representative images of aortic root sections stained for CD4 (arrows) and haematoxyline and cell number quantification. Scale bars are $100 \mu \mathrm{m}$. (B) A flowcharts and quantifications of total CD4 ${ }^{+} \mathrm{T}$ cells, naive $\mathrm{CD}^{+}{ }^{\mathrm{T}}$ cells $\left(\mathrm{CD} 62 \mathrm{I}^{+} \mathrm{CD} 44^{-}\right)$, effector $\mathrm{CD} 4^{+} \mathrm{T}$ cells $\left(\mathrm{CD} 62 \mathrm{I}^{-} \mathrm{CD} 44^{+}\right)$, and effector memory CD4 T cells $\left(\mathrm{CD} 62 \mathrm{I}^{+} \mathrm{CD} 44^{+}\right)$in splenocytes. $(C)$ Flow cytometry quantifications of regulatory T cells $\left(\right.$ FoxP $\left.3^{+}\right)$, Th17 $\left(\right.$RORyt $\left.^{+}\right)$, Th1 $\left(\mathrm{T}_{\text {-bet }}{ }^{+}\right)$, and Th2 $\left(\right.$Gata- $\left.3^{+}\right)$cells in splenocytes. $(D) B$ cells from mice treated with PBS or an agonistic BTLA antibody for 2 weeks were co-cultured with isolated CD4 ${ }^{+} \mathrm{T}$ cells from OTII mice in the presence of OVA323 peptide $(1 \mu \mathrm{g} / \mathrm{mL})$. $\mathrm{CD}^{+}{ }^{\mathrm{T}}$ cells were harvested after $72 \mathrm{~h}$ and assessed with flow cytometry for regulatory $\mathrm{T}$ cells $\left(\mathrm{FoxP} 3^{+}\right)$, Th17 (RORyt $\left.{ }^{+}\right)$, Th1 (T-bet $\left.{ }^{+}\right)$, and Th2 $(\mathrm{Gata}-$ $3^{+}$) cells and $(E)$ for cytokine production. An ordinary one-way ANOVA test followed by a Holm-Sidak post hoc test was performed. Data are shown as mean \pm SEM, $n=9 / 12(* P<0.05$, **P<0.01, ***P<0.001, ****P<0.00001). Tregs, regulatory $T$ cells; Th, T helper cell.

Up to date, most research in relation to BTLA has focused on T cells, while it is most abundantly expressed on B cells. ${ }^{3,6,29,30}$ One apparent reason for this discrepancy could be that many inflammatory disorders are thought to be mainly T-cell driven. However, with the recognition of novel B-cell subsets, we gained significantly more insight into the actual contribution of $B$ cells to inflammatory disorders. In atherosclerosis, we now know that B1 cells, ${ }^{19,31}$ marginal zone $B$ cells, ${ }^{25}$ and regulatory $B$ cells $^{32}$ can exert protective functions, contrary to follicular B cells that aggravate atherosclerosis. ${ }^{20,21}$ Since follicular B cells are in the majority, complete B2 cell depletion has resulted in attenuated atherosclerosis. ${ }^{20,21}$ Yet, these treatments deplete the complete B2 cell population which includes atheroprotective Bregs and marginal zone $B$ cells. ${ }^{20,21,33}$ In a side-to-side comparison study, we show that whereas anti-CD20 treatment depletes all B cells, BTLA specifically targets follicular B2 cells and can directly inhibit pro-inflammatory $\mathrm{CD}^{+} \mathrm{T}$ cells. Secondly, the humoral immunity is compromised with complete B2 cell depletion, illustrated by reductions in both total and antigen-specific $\lg G$ and $\lg M$ antibodies. ${ }^{20,21}$ In this study, we now describe that an agonistic antibody for BTLA specifically reduced, but not ablated, the atherogenic follicular B cells, while the atheroprotective B-cell subsets were increased. Although B cell depleting antibodies are already in clinical use for other autoimmune diseases such as rheumatoid arthritis, ${ }^{34}$ we believe that BTLA stimulation might be superior to total B-cell depletion in CVD. However, to confirm this, future atherosclerosis studies comparing agonistic BTLA treatment with total B-cell depletion should be performed. 
A

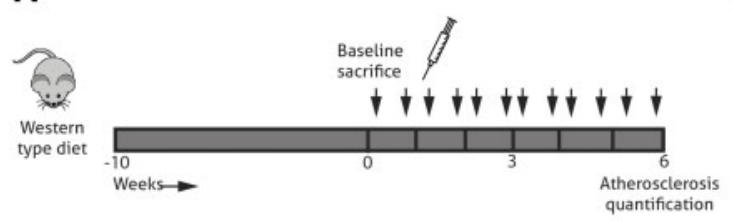

C

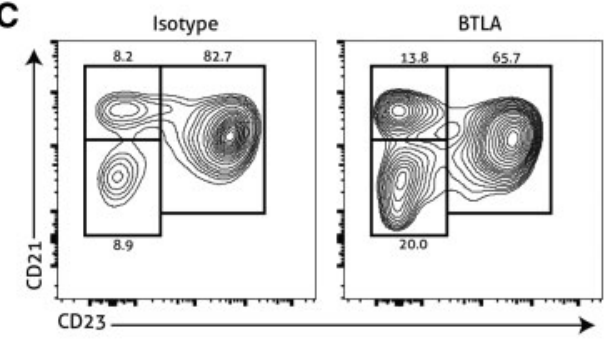

E

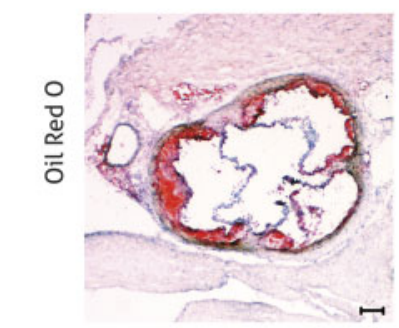

$\mathbf{F}$

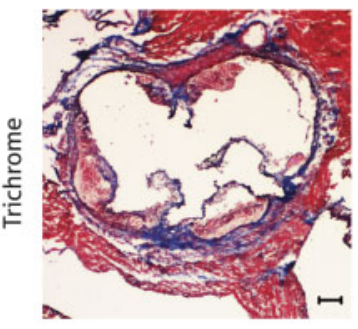

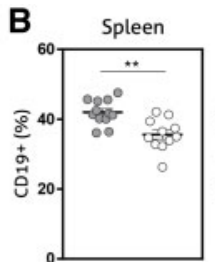

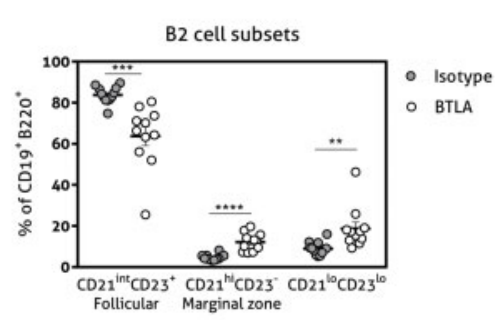

Isotype
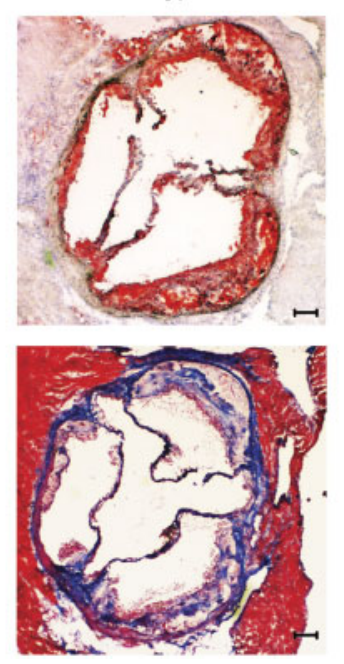

BTLA

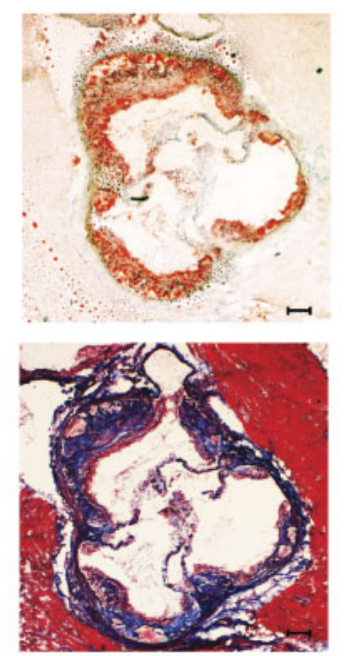

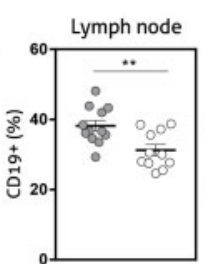

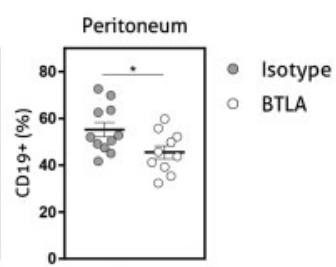

D
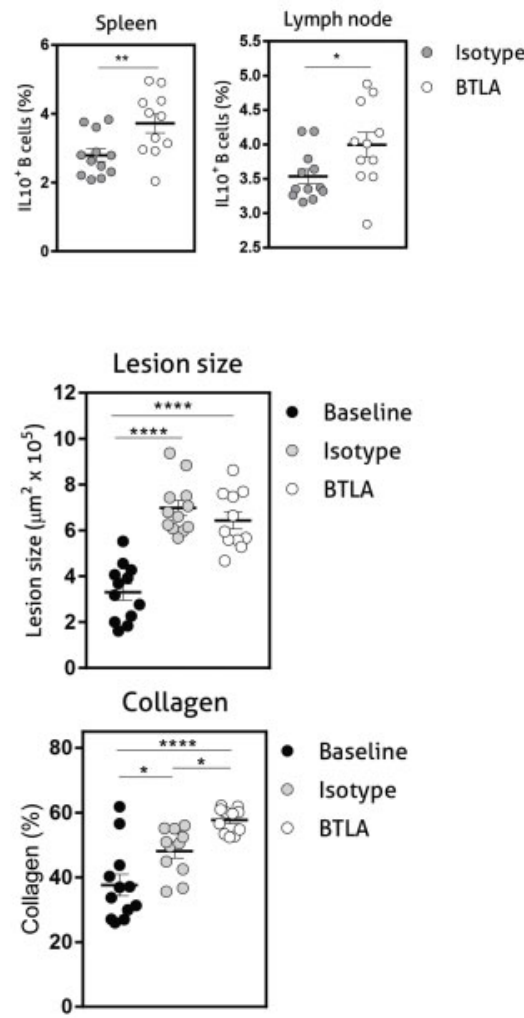

Figure 6 Activation of BTLA enhances collagen content in established lesions. (A) Female Ldlr-1- mice were fed a WTD for 10 weeks after which one group was sacrificed (baseline), while other mice were treated twice a week intraperitoneally with an isotype antibody or an agonistic BTLA antibody for 6 weeks. (B) Flow cytometry quantification of $B$ cells $\left(C D 19^{+}\right)$in different organs. (C) A flowcharts of splenocytes and quantification of follicular $\left(C D 21^{\text {int }} C D 23^{+}\right)$, marginal zone $\left(C D 21^{\text {hi }} C D 23^{-}\right)$, and newly formed $\left(C D 23^{\text {lo }} C D 21^{\text {lo }}\right)$ B cells in the spleen. (D) Flow cytometry quantification of regulatory $\mathrm{B}$ cells $\left(\mathrm{CD} 19^{+} \mathrm{IL}-10^{+}\right)$in spleen and lymph node. (E) Oil-Red-O and haematoxylin staining in aortic root sections and lesion size quantification. $(F)$ Trichrome staining in aortic root sections and collagen quantification. Scale bars are $100 \mu \mathrm{m}$. A Student's $t$-test was performed for two groups or an ordinary one-way ANOVA test followed by a Holm-Sidak post hoc test for multiple groups. Data are shown as mean \pm SEM $n=11-12(* P<0.05$, **P< 0.01 , ***P< $0.001, * * * * P<0.0001)$.

Additionally, we have found that the humoral immunity was not affected since both total and antigen-specific $\lg G 1, \lg G 2$, and $\lg M$ levels remained the same. This is in line with others that showed that blockade of the HVEM/BTLA pathway also did not alter the humoral effect following transplantation. ${ }^{35}$ This highlights the potential benefits of using an agonistic BTLA antibody for the treatment of atherosclerosis.

Besides reducing atherogenic follicular B2 cells, we found that BTLA activation resulted in a splenic B-cell population enriched in atheroprotective marginal zone $B$ cells and Bregs. Bregs have shown great protective potential in autoimmune disorders such as collageninduced arthritis and experimental autoimmune encephalomyelitis, primarily through their production of IL-10. ${ }^{22}$ Studies investigating the role of Bregs in atherosclerosis show conflicting results. ${ }^{18,32,36}$
However, recently, we found a very strong inverse correlation between atherosclerosis severity and the frequency of $\mathrm{IL}-10^{+} \mathrm{B}$ cells, and adoptive transfer of $\mathrm{IL}-10^{+} \mathrm{B}$ cells strongly reduced circulating leucocyte numbers and inflammatory monocytes in $\mathrm{Ldll}^{-1-}$ mice $^{37}$ Moreover, blockade of TIM-1, another immune checkpoint protein strongly associated with increased IL-10 producing B cells, ${ }^{24}$ leads to aggravated atherosclerosis, potentially via the blockade of TIM-1 ${ }^{+}$ B cells. ${ }^{38}$ Since BTLA agonism strongly increased B10 cells and $\mathrm{TIM}-1^{+} \mathrm{B}$ cells, we believe this contributed to the reduction of atherosclerosis.

In the last years, it has been increasingly recognized that B cells have an important cellular function independent of antibody production. We found that the altered B-cell population led to strongly decreased T-cell activation. In addition, we showed that in both atherosclerosis studies 
and in the B-T cell co-cultures, BTLA activation resulted in increased Tregs. During many autoimmune disorders, including atherosclerosis, Tregs become dysfunctional and are unable to curb disease. ${ }^{26}$ Restoration of this function or expansion of Tregs has been protective in atherosclerosis. ${ }^{26}$ Interestingly, it has previously been demonstrated that in experimental autoimmune encephalomyelitis, Bregs are able to recover the inhibitory activity of Tregs in a BTLA-dependent manner. ${ }^{39}$ Enhanced inhibitory activity of Tregs, could also explain the decrease in T-cell activation found in this study. In our B-T-cell co-cultures, we show BTLA activation promotes an increase in IL-5, which has been shown to induce Tregs ${ }^{40}$ and a decrease in the pro-inflammatory cytokine TNF $\alpha$, which further support a decrease in inflammatory response after BTLA activation. Furthermore, we show that the BTLA antibody also directly inhibits pro-inflammatory $T$ cells under hypercholesterolaemic conditions. Overall, the expansion of Bregs and Tregs could have greatly contributed to the atheroprotective effects found with BTLA activation. Future studies employing mice deficient for Tregs or B cells could provide more mechanistic insights into the atheroprotective effect of BTLA agonism.

Nowadays, tremendous efforts are undertaken in the clinic to identify and treat vulnerable lesions that are prone to rupture. ${ }^{41}$ By stimulating the BTLA pathway we were able to both reduce lesion size in an initiation study and also enhance collagen content, an important feature of stable lesion, during progression of atherosclerosis. The latter underscores that modulating the BTLA pathway presents a very promising option for clinical use. In addition, we found that in CVD patients almost $90 \%$ of all circulating B cells still express high levels of BTLA. Despite our limited sample number, this suggests that BTLA is also an interesting and accessible target in CVD patients.

In summary, treatment with an agonistic BTLA antibody prevents atherosclerosis and increases collagen content in already established lesions by favourably shifting the balance between atherogenic follicular B cells and atheroprotective $\mathrm{B}$ cells and directing $\mathrm{CD} 4^{+} \mathrm{T}$ cells towards Tregs. Our data strongly indicate that BTLA activation may be considered for the treatment of atherosclerosis.

\section{Supplementary material}

Supplementary material is available at Cardiovascular Research online.

\section{Acknowledgements}

We thank Maria Ozsvar Kozma for her technical assistance with the antibody measurements.

\section{Conflict of interest: none declared.}

\section{Funding}

This work was supported by the European Union's Seventh Framework [603131 to J.K.], by contributions from Academic and SME/industrial partners and supported by the Netherlands Heart Foundation [2016T008 to A.C.F.].

\section{References}

1. Libby P, Lichtman AH, Hansson GK. Immune effector mechanisms implicated in atherosclerosis: from mice to humans. Immunity 2013;38:1092-1104.

2. Foks AC, Kuiper J. Immune checkpoint proteins: exploring their therapeutic potential to regulate atherosclerosis. BrJ Pharmacol 2017;174:3940-3955.
3. Watanabe N, Gavrieli M, Sedy JR, Yang J, Fallarino F, Loftin SK, Hurchla MA, Zimmerman N, Sim J, Zang X, Murphy TL, Russell JH, Allison JP, Murphy KM. BTLA is a lymphocyte inhibitory receptor with similarities to CTLA-4 and PD-1. Nat Immunol 2003;4:670-679.

4. Sedy JR, Gavrieli M, Potter KG, Hurchla MA, Lindsley RC, Hildner K, Scheu S, Pfeffer K, Ware CF, Murphy TL, Murphy KM. B and T lymphocyte attenuator regulates T cell activation through interaction with herpesvirus entry mediator. Nat Immunol 2005;6:90-98.

5. Han P, Goularte OD, Rufner K, Wilkinson B, Kaye J. An inhibitory Ig superfamily protein expressed by lymphocytes and APCs is also an early marker of thymocyte positive selection. J Immunol 2004;172:5931-5939.

6. Krieg C, Han P, Stone R, Goularte OD, Kaye J. Functional analysis of B and T lymphocyte attenuator engagement on CD4+ and CD8+ T cells. J Immunol 2005;175: 6420-6427.

7. Oya Y, Watanabe N, Owada T, Oki M, Hirose K, Suto A, Kagami S-I, Nakajima H, Kishimoto T, Iwamoto I, Murphy TL, Murphy KM, Saito Y. Development of autoimmune hepatitis-like disease and production of autoantibodies to nuclear antigens in mice lacking B and T lymphocyte attenuator. Arthritis Rheum 2008;58:2498-2510.

8. Wang X-F, Chen Y-J, Wang Q, Ge Y, Dai Q, Yang K-F, Zhou Y-H, Hu Y-M, Mao Y$X$, Zhang $X-G$. Distinct expression and inhibitory function of $B$ and $T$ lymphocyte attenuator on human T cells. Tissue Antigens 2007;69:145-153.

9. Oki M, Watanabe N, Owada T, Oya Y, Ikeda K, Saito Y, Matsumura R, Seto Y, Iwamoto I, Nakajima H. A functional polymorphism in B and T lymphocyte attenuator is associated with susceptibility to rheumatoid arthritis. Clin Dev Immunol 2011; 2011:305656.

10. Pruul K, Kisand K, Alnek K, Metsküla K, Reimand K, Heilman K, Peet A, Varik K, Peetsalu M, Einberg Ü, Tillmann V, Uibo R. Differences in B7 and CD28 family gene expression in the peripheral blood between newly diagnosed young-onset and adultonset type 1 diabetes patients. Mol Cell Endocrinol 2015;412:265-271.

11. Spodzieja M, Lach S, Iwaszkiewicz J, Cesson V, Kalejta K, Olive D, Michielin O, Speiser DE, Zoete V, Derré L, Rodziewicz-Motowidło S. Design of short peptides to block BTLA/HVEM interactions for promoting anticancer T-cell responses. PLoS One 2017;12:e0179201.

12. Ye Z, Deng B, Wang C, Zhang D, Kijlstra A, Yang P. Decreased B and T lymphocyte attenuator in Behcet's disease may trigger abnormal Th17 and Th1 immune responses. Sci Rep 2016;6:20401.

13. Lepenies B, Pfeffer K, Hurchla MA, Murphy TL, Murphy KM, Oetzel J, Fleischer B, Jacobs $T$. Ligation of $B$ and $T$ lymphocyte attenuator prevents the genesis of experimental cerebral malaria. J Immunol 2007;179:4093-4100.

14. Albring JC, Sandau MM, Rapaport AS, Edelson BT, Satpathy A, Mashayekhi M, Lathrop SK, Hsieh C-S, Stelljes M, Colonna M, Murphy TL, Murphy KM. Targeting of $B$ and $T$ lymphocyte associated (BTLA) prevents graft-versus-host disease without global immunosuppression. J Exp Med 2010;207:2551-2559.

15. Uchiyama M, Jin X, Matsuda $H$, Bashuda H, Imazuru T, Shimokawa T, Yagita H, Niimi M. An agonistic anti-BTLA mAb (3C10) induced generation of IL-10-dependent regulatory CD4+ T cells and prolongation of murine cardiac allograft. Transplantation 2014;97:301-309.

16. Van Brussel I, Ammi R, Rombouts M, Cools N, Vercauteren SR, De Roover D, Hendriks JMH, Lauwers P, Van Schil PE, Schrijvers DM. Fluorescent activated cell sorting: an effective approach to study dendritic cell subsets in human atherosclerotic plaques. J Immunol Methods 2015;417:76-85.

17. Gruber S, Hendrikx T, Tsiantoulas D, Ozsvar-Kozma M, Göderle L, Mallat Z, Witztum JL, Shiri-Sverdlov R, Nitschke L, Binder CJ. Sialic acid-binding immunoglobulin-like lectin $\mathrm{G}$ promotes atherosclerosis and liver inflammation by suppressing the protective functions of B-1 cells. Cell Rep 2016;14:2348-2361.

18. Douna H, Kuiper J. Novel B-cell subsets in atherosclerosis. Curr Opin Lipidol 2016;27: 493-498.

19. Kyaw T, Tay C, Hosseini H, Kanellakis P, Gadowski T, MacKay F, Tipping P, Bobik A, Toh B-H. Depletion of B2 but not B1a B cells in BAFF receptor-deficient ApoE mice attenuates atherosclerosis by potently ameliorating arterial inflammation. PLoS One 2012; 7:e29371.

20. Kyaw T, Cui P, Tay C, Kanellakis P, Hosseini H, Liu E, Rolink AG, Tipping P, Bobik A, Toh B-H. BAFF receptor mAb treatment ameliorates development and progression of atherosclerosis in hyperlipidemic ApoE(-/-) mice. PLoS One 2013;8:e60430.

21. Ait-Oufella H, Herbin O, Bouaziz J-D, Binder CJ, Uyttenhove C, Laurans L, Taleb S, Vré EV, Esposito B, Vilar J, Sirvent J, Snick JV, Tedgui A, Tedder TF, Mallat Z. B cell depletion reduces the development of atherosclerosis in mice. J Exp Med 2010;207: 1579-1587.

22. Mauri C, Menon M. The expanding family of regulatory B cells. Int Immunol 2015;27: $479-486$.

23. Yanaba K, Bouaziz J-D, Haas KM, Poe JC, Fujimoto M, Tedder TF. A regulatory B cell subset with a unique CD1dhiCD5+ phenotype controls T cell-dependent inflammatory responses. Immunity 2008;28:639-650.

24. Ding Q, Yeung M, Camirand G, Zeng Q, Akiba H, Yagita H, Chalasani G, Sayegh MH, Najafian N, Rothstein DM. Regulatory B cells are identified by expression of TIM-1 and can be induced through TIM-1 ligation to promote tolerance in mice. J Clin Invest 2011;121:3645-3656. 
25. Nus M, Sage AP, Lu Y, Masters L, Lam BYH, Newland S, Weller S, Tsiantoulas D, Raffort J, Marcus D, Finigan A, Kitt L, Figg N, Schirmbeck R, Kneilling M, Yeo GSH, Binder CJ, Pompa J. D L, Mallat Z. Marginal zone B cells control the response of follicular helper T cells to a high-cholesterol diet. Nat Med 2017;23:601-610.

26. Foks AC, Lichtman AH, Kuiper J. Treating atherosclerosis with regulatory $\mathrm{T}$ cells. Arterioscler Thromb Vasc Biol 2015;35:280-287.

27. Halvorsen B, Otterdal K, Dahl TB, Skjelland M, Gullestad L, Øie E, Aukrust P. Atherosclerotic plaque stability - what determines the fate of a plaque? Prog Cardiovasc Dis 2008;51:183-194.

28. Ridker PM, Everett BM, Thuren T, MacFadyen JG, Chang WH, Ballantyne C, Fonseca F, Nicolau J, Koenig W, Anker SD, Kastelein JJP, Cornel JH, Pais P, Pella D, Genest J, Cifkova R, Lorenzatti A, Forster T, Kobalava Z, Vida-Simiti L, Flather M, Shimokawa H, Ogawa H, Dellborg M, Rossi PRF, Troquay RPT, Libby P, Glynn RJ; CANTOS Trial Group. Antiinflammatory therapy with canakinumab for atherosclerotic disease. N Engl J Med 2017;377:1119-1131.

29. Yuan B, Zhao L, Fu F, Liu Y, Lin C, Wu X, Shen H, Yang Z. A novel nanoparticle containing MOG peptide with BTLA induces $T$ cell tolerance and prevents multiple sclerosis. Mol Immunol 2014;57:93-99.

30. Yang B, Huang Z, Feng W, Wei W, Zhang J, Liao Y, Li L, Liu X, Wu Z, Cai B, Bai Y, Wang $L$. The expression of BTLA was increased and the expression of HVEM and LIGHT were decreased in the T cells of patients with rheumatoid arthritis [corrected]. PLoS One 2016;11:e0155345.

31. Kyaw T, Tay C, Krishnamurthi S, Kanellakis P, Agrotis A, Tipping P, Bobik A, Toh B$\mathrm{H}$. B1a B lymphocytes are atheroprotective by secreting natural IgM that increases IgM deposits and reduces necrotic cores in atherosclerotic lesions. Circ Res 2011; 109:830-840.

32. Strom AC, Cross AJ, Cole JE, Blair PA, Leib C, Goddard ME, Rosser EC, Park I, Hultgårdh Nilsson A, Nilsson J, Mauri C, Monaco C. B regulatory cells are increased in hypercholesterolaemic mice and protect from lesion development via IL-10. Thromb Haemost 2015;114:835-847.
33. Matsushita T, Yanaba K, Bouaziz J-D, Fujimoto M, Tedder TF. Regulatory B cells inhibit EAE initiation in mice while other $B$ cells promote disease progression. J Clin Invest 2008;118:3420-3430.

34. Edwards JCW, Szczepański L, Szechiński J, Filipowicz-Sosnowska A, Emery P, Close DR, Stevens RM, Shaw T. Efficacy of B-cell-targeted therapy with rituximab in patients with rheumatoid arthritis. N Engl J Med 2004;350:2572-2581.

35. Rodriguez-Barbosa J-I, Fernandez-Renedo C, Moral AMB, Bühler L, Rio M-L. D. T follicular helper expansion and humoral-mediated rejection are independent of the HVEM/BTLA pathway. Cell Mol Immunol 2017;14:497-510.

36. Sage AP, Nus M, Baker LL, Finigan AJ, Masters LM, Mallat Z. Regulatory B cellspecific interleukin-10 is dispensable for atherosclerosis development in mice. Arterioscler Thromb Vasc Biol 2015;35:1770-1773.

37. Douna H, Amersfoort J, Schaftenaar FH, Kroon S, Puijvelde G. V, Kuiper J, Foks AC. Bidirectional effects of IL-10+ regulatory B cells in $\mathrm{Ldlr}^{-/-}$mice. Atherosclerosis 2019; 280:118-125.

38. Foks AC, Engelbertsen D, Kuperwaser F, Alberts-Grill N, Gonen A, Witztum lL, Lederer J, Jarolim P, DeKruyff RH, Freeman GJ, Lichtman AH. Blockade of Tim-1 and Tim-4 enhances atherosclerosis in low-density lipoprotein receptor-deficient mice. Arterioscler Thromb Vasc Biol 2016;36:456-465.

39. Huarte E, Jun S, Rynda-Apple A, Golden S, Jackiw L, Hoffman C, Maddaloni M, Pascual DW. Regulatory $T$ cell dysfunction acquiesces to BTLA+ regulatory $B$ cells subsequent to oral intervention in experimental autoimmune encephalomyelitis. J Immunol 2016;196:5036-5046.

40. Tran GT, Hodgkinson SJ, Carter NM, Verma ND, Plain KM, Boyd R, Robinson CM, Nomura M, Killingsworth M, Hall BM. IL-5 promotes induction of antigen-specific CD4+CD25+ T regulatory cells that suppress autoimmunity. Blood 2012;119: $4441-4450$.

41. Stefanadis C, Antoniou C-K, Tsiachris D, Pietri P. Coronary atherosclerotic vulnerable plaque: current perspectives. J Am Heart Assoc 2017;6:e005543. 